\section{KẾT LUẦN}

- Sau 2 tháng điều tri bằng chễ phẩm Tavinga trên 56 bệnh nhân phì đại lành tính tuyến tiên liệt, các triệu chứng rối loạn tiểu tiện đã được cải thiện rõ rệt, điểm trung bình IPSS trung bình giảm từ $17,62 \pm 7,42$ xuống còn $4,84 \pm 3,75$; Điểm chất lượng cuộc sống QoL trung bình giảm từ $3,90 \pm 0,47$ xuống còn $1,70 \pm 0,35$; lưu lượng nước tiểu trung bình tăng từ 4,26 $\pm 2,65$ lên 8,76 $\pm 2,97$; thể tích nước tiểu tồn dư giảm từ 35,34 \pm $12,86 \mathrm{ml}$ xuống còn $14,51 \pm 10,29 \mathrm{ml}$; kích thước thể tích tuyến tiền liệt trung bình giảm giảm trung bình $13,82 \mathrm{~cm}^{3}$. Sức khỏe bênh nhân được cải thiện như ăn ngủ tốt, tiêu hóa cải thiện, tinh thần thoải mái, chức năng sinh lý được cải thiện.

- Tavinga không các biến đổi các chỉ số sinh hóa, huyết học và không thây các tác dụng không mong muốn của sản phẩm sau 2 tháng điều trị.
TÀI LIỆ THAM KHẢO

1. Nguyễn Bửu Triều, Lê Ngọc Từ (2003), U phì đại lành tính tuyến tiền liệt," Bệnh học tiết niệu, Nhà Xuất bản Y học, Hà Nội, tr.400-498.

2. Trân Đức, Trân Đức Hòe (2000), Sử dung IPSS QoL và đo lưu lượng nước tiểu trong đánh giá kết quả phẫu thuật u phì đại lành tính tuyến tiên liệt, Tạp chí Y học thực hành 7-2000, tr. 32-35.

3. Quyêt định số 46/2007/QĐ-BYT ngày 19/12/2007 của Bộ Y tế về chỉ tiêu kim loại nặng, vi sinh vật gây hại trong thực phẩm và dược phẩm.

4. Trân Lập Công (2011), Ṅghiên cứu hiệu quả điều trị phì đại lành tính tuyến tiền liệt của trà tan "Thủy long", Luận án tiến sĩ y học, Nà Nội, 2011.

5. Hoàng Văn Huấn, Phạm Khẳc Linh, Nguyễn Như Nghĩa, Nguyễn Quốc Ân, Phạm Xuân Ninh, Ngô Thanh Nam, Pham Ngọc Quang (2012), Kết quả ứng dụng chể phẩm peptit điều hòa sinh học hỗ trợ điều trị cho những người có tiên sử tiếp xúc với chất đốc da cam/dioxin bi phì đai lành tính tuyến tiên liệt, Tạp chí Khoa học và Cồng nghệ nhiệt đới, số 01, 12-2012, tr. 85-93ं.

\title{
BƯớC ĐẦU ĐÁNH GIÁ TÌNH TRANG MẤT NGỦ KHÔNG THỰC TỔN VÀ MộT Số YẾU TỐ LIÊN QUAN
}

\section{TÓM TẮT}

Mục tiêu: Đánh giá tình trạng mất ngủ không thực tổn thể Tâm tỳ hư và một số yếu tố liên quan. Đối tượng và phương pháp: 60 bệnh nhân tuổi trên 18, được chẩn đoán xác định mất ngủ không thực tổn theo tiêu chuẩn ICD - 10, phù hợp chứng Thất miên thể tâm tỳ hư theo $\mathrm{Y}$ học cổ truyền, điều trị tại Bệnh viện Châm Cứu Trung ương và Bệnh viện Tuệ Tĩnh từ tháng 5/2019 đến 10/2019, không phẩn biệt giới tính, nghề nghiệp, tình nguyện tham gia nghiên cứu. Đánh giá đặc điểm chung các đối tượng nghiên cứu, triệu chứng lâm sàng liên quan giấc ngủ. Kết quả: $90 \%$ bệnh nhânmất ngủ có độ tuổi trên 40 , tuổi mắc bệnh trung bình $57,60 \pm 15,58$ tuổi. Thời gian mắc bệnh từ 3 tới 6 tháng chiếm tỷ lệ cao $(63,3 \%)$. Thời lượng giấc ngủ trung bình trong đêm đạt 4,02 \pm 0,53 (giờ). Điểm đánh giá chất lượng giấc ngủ PSQI trung bình 14,09 $\pm 2,22$ (điểm). Áp lực công việc, mâu thuẫn gia đình, tổn thất kinh tế là những nguyên nhân gây sang chấn tâm lý thường gặp ở các bệnh nhân nghiên cứu. Kết luận: Mất ngủ không thực tổn gây ảnh hưởng nhiều tới chất lượng cuộc sống, lao

${ }^{1}$ Bệnh viện Châm cứu Trung ương,

2Viện Y học cổ truyền Quân đồi

Chịu trách nhiệm chính: Nguyễn Đức Minh

Email: drminhchamcuu@gmail.com

Ngày nhận bài: 10/12/ 2020

Ngày phản biện khoa học: 8/1/2021

Ngày duyệt bài: 29/1/2021

\section{Nguyễn Đức Minh ${ }^{1}$, Nguyễn Vinh Quốc ${ }^{2}$}

động và sinh hoạt của người bệnh. Bệnh có liên quan tới tuổi, nghề nghiệp, tình trạng hôn nhân và tiên sử sang chấn tâm lý.

Tư khóa: Mất ngủ không thực tổn, thất miên.

\section{SUMMARY}

ASSESSMENT OF PATIENTS WITH

NONORGANIC INSOMNIA AND SOME RELATED FACTORS

Objectives: To evaluate the nonorganic insomnia with xinpixuand some related factors. Subjects and method: 60 volunteered patients aging over 18 years old, which were diagnosed with nonorganic insomnia by ICD-10, consistent with shimian of xinpixu by traditional medicine, were getting treatment at Central Acupuncture Hospital and Tue Tinh Hospital from 2019 May to 2019 October; irrespective of occupation, gender. Generalizing the characterization of the patients, sleep-related clinical symptoms. Results: $90 \%$ of insomnia patients were over 40 years old, the age average is $57,60 \pm 15,58$ (years) with $63.3 \%$ patients had the duration of illness from 3 to 6 months. The average sleep duration during the night was $4.02 \pm 0.53$ (hour). The averaged PSQI score was $14.09 \pm 2.22$. Working pressure, family conflicts, and economic losses are common causes of trauma in the study patients. Conclusion: Nonorganic insomnia affect the quality of life, labor and living of the patient. The disease is related to age, occupation, marital status and history of trauma.

Keywords: Nonorganic insomnia, shimian 


\section{I. ĐẶT VẤN ĐỀ}

Giấc ngủ là hoạt động sinh lý bình thường nhằm đảm bảo sức khỏe con người. Rối loạn giấc ngủ là trạng thái không thoải mái về sô lượng và chất lượng của giấc ngủ do nhiều nguyên nhân khác nhau gây nên[1]. Bênh lý này được mô tả trong phạm trù chứng "Thất miên" của Y học cổ truyền[2]. Tại Việt Nam, rối loạn giấc ngủ chiếm tỷ lệ cao (50-80\%) và là nguyển nhân gây ra các rối loạn trầm cảm, rối loạn lo âu và các bệnh lý tâm sinh[1], [3]. Mất ngủ không thực tổn, một dạng của rối loạn giấc ngủ hiện đang là vấn đề được các nhà nghiên cứu trển thế giới cũng như trong nước và cộng đồng xã hội quan tâm đặc biệt vì nó ảnh hưởng trực tiếp đến sức khỏe, chất lượng cuộc sống hàng ngày và khả năng hoạt động xã hội, thậm chí có thể dẫn đến tai nạn nghiêm trọng, làm tăng tỷ lệ mắc bệnh và có thể dẫn tới tử vong[1].

Năm 2019, Bệnh viện Châm Cứu Trung ương và Bệnh viện Tuể Tĩnhđã tiếp nhận điều trị nhiều bệnh nhân rối loạn giấc ngủ không thực tổn. Để có cơ sở xây dựng phác đồ điều trị phù hợp, hiệu quả, góp phần mang lại sức khỏe cho người bệnh. Nghiên cứu được thực hiện nhằm mục tiêu đánh giá tình trạng mất ngủ không thực tổn thể Tâm tỳ hư và một số yếu tố liên quan.

\section{II. ĐỐI TƯợNG VÀ PHƯƠNG PHÁP NGHIÊN CỨU}

2.1. Đối tượng nghiên cứu. 60 bệnh nhân (BN) tuổi trên 18, được chẩn đoán xác định mất ngủ không thực tổntheo tiêu chuẩn của ICD - 10 mục F51.0[4], phù hợp chứng Thất miên thể tâm tỳ hư theo $Y$ học cố truyền[2]. Không phân biệt giới tính, nghề nghiệp, tình nguyện tham gia nghiên cứu. Điều trị tại Bệnh viện Châm Cứu Trung ương và Bệnh viện Tuệ Tĩnh từ tháng $5 / 2019$ đến tháng $10 / 2019$. Không đưa vào nghiên cứu những trường hợp BN mất ngủ có thực tổn, tổn thương hệ thần kinh, rối loạn tâm thẩn, có các bệnh nhiếm trùng cấp tính, phụ nữ có thai và đang cho con bú.

2.2. Phương pháp nghiên cứu. Nghiên cứu mô tả, phân tích, tổng hợp số liệu qua hồ sơ bệnh án $B N$ được lưu trữ tại hai bệnh viện.

\subsection{Chỉ tiêu theo dõi và đánh giá}

- Đặc điểm chung các BN nghiên cứu: Tuổi, giới tính, nghề nghiệp, thời gian mắc bệnh, hoàn cảnh gia đình, tiền sử sang chấn tâm lý.

- Đánh giá triệu chứng lâm sàng liên quan giấc ngủ: thời gian vào giấc ngủ, chất lượng giấc ngủ (tính bằng tỷ lệ \% số giờ ngủ/số giờ nằm trên giường, phân thành các mức độ: Tốt khi hiệu quả giấc ngủ $\geq 85 \%$, trung bình khi hiệu quả giấc ngủ 75\%-84\%, kém khi hiệu quả giấc ngủ $65 \%-74 \%$ và rất kém khi hiệu quả giấc ngủ $<65 \%$ ), tần suất rối loạn ngủ (số lần thức giấc sớm/tuần), thời gian ngủ trong đêm, đánh giá chất lượng giấc ngủ theo thang điểm PSQI, cáctriệu chứng khác kèm theo (mệt mỏi, gầy sút cân, giảm tập trung chú ý, lo lắng, hay quên, dễ cáu gắt, hoa mắt chóng mặt).

2.4. Xử lý số liệu. Số liệu thu thập được xử lý bằng phần mềm SPSS 16.0 for Windows. Sử dụng các thuật toán tính tỷ lệ phần trăm, tính số trung bình, độ lệch chuẩn.

\section{KẾT QUẢ NGHIÊN CỨU}

Bảng 1. Đặc điểm chung các đôi tượng nghiên cứu

\begin{tabular}{|c|c|c|c|}
\hline \multicolumn{2}{|c|}{ Chỉ tiêu } & Số lượng & Tỷ lệ \% \\
\hline \multirow{6}{*}{ Tuổi } & $16-29$ & 3 & 5 \\
\hline & $30-39$ & 3 & 5 \\
\hline & $40-49$ & 12 & 20 \\
\hline & $50-59$ & 12 & 20 \\
\hline & $\geq 60$ & 30 & 50 \\
\hline & \multicolumn{3}{|c|}{$\begin{array}{l}\text { Tuối trung bình (năm; } \bar{X} \pm \text { SD): } \\
57,60 \pm 15,58\end{array}$} \\
\hline \multirow{2}{*}{ Giới tính } & Nam & 27 & 45 \\
\hline & Nũ & 33 & 55 \\
\hline \multirow{4}{*}{$\begin{array}{l}\text { Nghêe } \\
\text { nghiệp }\end{array}$} & Nông dân & 02 & 3,3 \\
\hline & Công nhân & 03 & 5 \\
\hline & Lao động trí óc & 31 & 51,7 \\
\hline & Lao động tự do & 24 & 40 \\
\hline \multirow{3}{*}{$\begin{array}{l}\text { Thời gian } \\
\text { mắc bệnh }\end{array}$} & $<3$ tháng & 7 & 11,7 \\
\hline & $3-<6$ tháng & 38 & 63,3 \\
\hline & $\geq 6$ tháng & 15 & 25 \\
\hline \multirow{2}{*}{$\begin{array}{l}\text { Đắc điểm } \\
\text { hồn nhân }\end{array}$} & Độc thân & 1 & 0,7 \\
\hline & Đã kết hôn & 59 & 98,3 \\
\hline \multirow{4}{*}{$\begin{array}{l}\text { Tiền sử } \\
\text { sang chấn } \\
\text { tâm lý }\end{array}$} & Áp lực công việc & 25 & 41,7 \\
\hline & Thiệt hại kinh tế & 9 & 15 \\
\hline & $\begin{array}{l}\text { Mấu thuân gia } \\
\text { đình }\end{array}$ & 10 & 16,7 \\
\hline & Khác & 16 & 26,6 \\
\hline
\end{tabular}

BN mất ngủ có độ tuối trên 40 tuổi chiếm tỷlệ cao $(90 \%)$, tuổi mắc bệnh trung bình là $57,60 \pm$ 15,58 . Tỷ lệ mắc bệnh ở nữ giới có xu hướng cao hơn nam giới. Chủ yếu mất ngủ không thực tổn gặp ở đối tượng lao động trí óc và lao động tự do $(91,7 \%)$, hầu hết đã có gia đình. Thời gian mắc bệnh từ 3 tới 6 tháng chiếm tỷ lệ cao (63,3\%). Áp lực công việc, mâu thuẫn gia đình, tổn thất kinh tế là những nguyên nhân gây sang chấn tâm lý thường gặp ở các đối tượng tham gia nghiên cứu.

Bảng 2. Các triệu chứng lâm sàng liên quan giấc ngủ

\begin{tabular}{|l|c|c|} 
Chỉ tiêu & $\begin{array}{c}\text { Số } \\
\text { lượng }\end{array}$ & $\begin{array}{c}\text { Tỷ lệ } \\
\%\end{array}$ \\
\hline
\end{tabular}




\begin{tabular}{|c|c|c|c|}
\hline \multirow{4}{*}{$\begin{array}{l}\text { Thời gian vào } \\
\text { giấc ngủ (phút) }\end{array}$} & $<15$ & 0 & 0,0 \\
\hline & $16-30$ & 1 & 1,7 \\
\hline & $31-60$ & 24 & 40,0 \\
\hline & $>60$ & 35 & 58,3 \\
\hline \multirow{4}{*}{$\begin{array}{l}\text { Chất lượng giấc } \\
\text { ngủ }\end{array}$} & Tốt & 0 & 0,0 \\
\hline & Trung bình & 22 & 36,7 \\
\hline & Kém & 38 & 63,3 \\
\hline & Rất kém & 0 & 0,0 \\
\hline \multirow{4}{*}{$\begin{array}{l}\text { Tần suất rối } \\
\text { loạn ngư } \\
\text { (lần/tuần) }\end{array}$} & 0 & 0 & 0,0 \\
\hline & 1 & 0 & 0,0 \\
\hline & 2 & 19 & 31,7 \\
\hline & $\geq 3$ & 41 & 68,3 \\
\hline \multicolumn{2}{|c|}{$\begin{array}{l}\text { Thời lượng giấc ngủ trung } \\
\text { bình trong đêm (giờ; } \bar{X} \pm S D \text { ) }\end{array}$} & \multicolumn{2}{|c|}{$4,02 \pm 0,53$} \\
\hline \multicolumn{2}{|c|}{$\begin{array}{l}\text { Điểm PSQI trung bình } \\
(\bar{X} \pm S D)\end{array}$} & \multicolumn{2}{|c|}{$14,09 \pm 2,22$} \\
\hline
\end{tabular}

Hầu hết các đối tượng tham gia nghiên cứu đều khó khăn khi vào giấc ngủ, 98,3\% phải sau ít nhất 30 phút mới vào được giấc ngủ. Tất cả đều tự đánh giá chất lượng giấc ngủ của bản thân ở mức trung bình và kém với thời lượng giấc ngủ trung bình trong đêm chỉ đạt 4,02 \pm 0,53giờ. Có $68,3 \%$ có số lần thức giấc sớm trên 3 lần/tuần. Điểm đánh giá chất lượng giấc ngủ PSQI trung bình là 14,09 $\pm 2,22$.

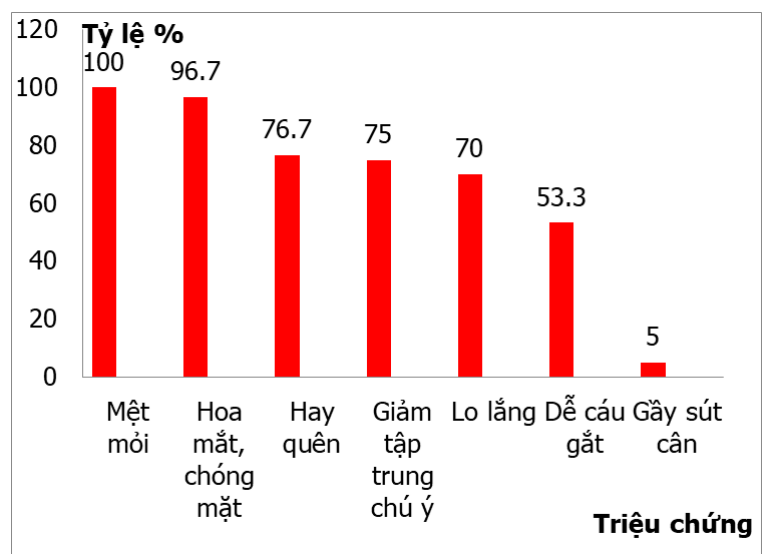

Biểu đồ 1. Các triệu chứng lâm sàng kèm theo

Các triệu chứng lâm sàng thường gặp kèm theo trên các $B N$ rối loạn giấc ngủ là: mệt mỏi $(100 \%)$; hoa mắt chóng mặt $(96,7 \%)$; hay quên $(76,7 \%)$; giảm tập trung chú ý $(75 \%)$; lo lắng (70\%); dễ cáu gắt $(53,3 \%)$.

\section{BÀN LUÂ̂N}

\subsection{Về đặc điểm chung của đối tượng} nghiên cứu

Tuổi: Trong nghiên cứu của chúng tôi, BN mất ngủ có độ tuổi trên 40 tuổi chiếm tỷ lệ cao $(90 \%)$ với tuổi mắc bệnh trung bình là $57,60 \pm$ 15,58 . Kết quả này phù hợp với các nghiên cứu của Wilsons (2008), Nguyễn Văn Tâm (2019)...[3], [5]. Thực tế cho thấy, độ tuổi càng cao con người càng có nhiều vấn đề cần quan tâm lo lắng. Bên cạnh những áp lực từ xã hội như công việc, thu nhập... thì các yếu tố về thể chất cũng tácđộng khônng nhỏ đến giấc ngủ của con người. $Y$ học cổ truyền cho rằng Âm huyết là phần vât chất quan trọng cấu thành cơ thể con người. Âm huyết hư sẽ gây kém ngủ, hơn nữa dương khí có đầy đủ hay không cũng phải nương nhờ âm huyết mà tồn tại. Sách Nội kinh viết "người đến 40 tuổi thì âm khíđã kém đến phân nửa", giấc ngủ thuộc phần âm, do vậy bệnh gặp nhiều ở lứa tuổi trên 40[2]. Tuệ Tĩnh trong Nam dược thần hiệu cho rằng: "Người già dương suy hay khi ốm mới khỏi còn yếu mà không ngủ được...[2]. Do đó tuổi cũng là một yếu tố ảnh hưởng đến giấc ngủ.

Giới tính: Tỷ lệ mắc rối loạn giấc ngủ ở nữ giới trong nghiên cứu có xu hướng cao hơn nam giới. Kết quả này phù hợp nhận định của Nguyễn Văn Tâm với tỷ lệ nữ/nam là $76,36 \% / 23,64 \%$; Nguyễn Ngọc Đăng với tỷ lệ nữ/nam là $72,25 \% / 27,75 \%$ và nhiêu tác giả khác [3],[6]... Nữ giới thường nhạy cảm, hay lo nghĩ dẫn đến stress nhiều hơn nam giới trong các vấn đề tình cảm, xã hội, công việc... Điều này có thể do trong cuộc sống hiện đại, người phụ nữ phải chịu áp lực công việc nhiều hơn nam giới vì ngoài công việc xã hội họ còn phải chăm lo, quan tâm, quán xuyến cho gia đình. Hơn nữa, nhiều nghiên cứu cho thấy mất ngủ ở nữ giới có liên quan đến chu kỳ kinh nguyệt, ở phụ nữ giai đoạn mãn kinh hoặc tiền mãn kinh thường hay căng thẳng, stress có liên quan mật thiết tới sự suy giảm nồng độ estrogen[7]. Theo Y học cổ truyền, người phụ nữ với thiên chức làm mẹ, sinh con và nuôi con nhỏ kéo dài nhiêu tháng, nhiều năm nên dễ làm rối loạn giấc ngủ cũng như hao tổn âm huyết. Sách Linh Khu viết "Người phụ nữ sinh ra, có thừa về Khí, bất túc về Huyết, là vì bị thoát huyết nhiều lần", huyết không nuôi Tâm nên tâm thần không yên mà dẫn đến không ngủ được[2].

Nghề nghiệp: chủ yếu mất ngủ không thực tổn gặp ở BN lao động trí óc (51,7\%). Lao động tri thức thường phải chịu nhiều căng thẳng từ áp lực công việc, chế độ sinh hoạt không điều độ, thời gian sử dụng máy tính nhiều, ít hoạt động thể lực... dẫn tới các thay đổi về hormone sinh dục, tâm sinh lý, mất cân bằng trạng thái cơ thểnên dễ xảy ra tình trạng khó ngủ và mất ngủ. Điều này phù hợp với nhận định của nhiều tác giả[1], [3], [6]. 
Thời gian mắc bênh: thời gian mắc bênh từ 3 tới 6 tháng chiếm tỷ lệ cao $(63,3 \%)$, cho thây tính chất của rối loạn giấc ngủ không thực tổn là diễn ra từ từ và mang tính chất man tính. Có thể do khi mới mắc bênh mất ngủ, người bênh còn chưa bị ảnh hưởng nhiều tới cuộc sống và sinh hoạt nên thường chủ quan, không điều trị hoặc tự mua thuốc điêuu tri. Chỉ tới khi tình trang mất ngủ kéo dài, tái phát nhiều lần gây ảnh hưởng tới chất lượng công việc và cuộc sống thì mới tìm tới các cơ sở y tế để được chăm sóc [1], [3], [6]. Điều này sẽ gây khó khăn và làm tăng gánh nặng cho cán bộ y tế khi thực hiện công tác điều trị. Do vậy theo chúng tôi, việc tăng cường giáo dục cộng đồng đối với bệnh lý này là hết sức cần thiết và có ý nghĩa.

Đặc điểm hôn nhân: hầu hết đã có gia đình, kết quả này nói lên mối quan hệ trong gia đình góp phần không nhỏ dẫn đến tình căng thẳng, stress từ đó dẫn đến mất ngủ. Đây cũng là nhận định của nhiều nghiên cứu: yếu tố gia đình có ảnh hưởng quan trọng tới chất lượng giấc ngủ[1], [3], [6]. Kết quả này cũng phù hợp với số liệu của chúng tôi khi thống kê được tỷ lệ mất ngủ gặp nhiều ở nữ hơn nam và có liên quan tới các vấn đề về tâm lý.

Tiền sử sang chấn tâm lý: áp lực công việc, mâu thuẫn gia đình, tổn thất kinh tế là những nguyên nhân gây sang chấn tâm lý thường gặp ở các đối tượng tham gia nghiên cứu, phù hợp với kết quả nhận thấy mất ngủ gặp nhiều ở đổi tượng là lao động trí óc hoặc lao động tự do mà chúng tôi đã khảo sát. Theo ICD10: "Mất ngủ phát triển ở thời điểm có stress tăng lên". Stress có thể gây hại đối với cơ thể vì nó phá vỡ hoạt động sinh lý và cảm xúc của cơ thể và có thể gây bệnh nễu diễn ra kéo dài[1], [5], [7]. Stress dẫn đến mất ngủ là nguyên nhân tiêu tốn của xã hội nhiều tỉ đô la mỗi năm, chưa kể đến những thiệt hại do căn bệnh mất ngủ gây ra cho con người là những vấn đề rắc rối về sức khỏe như các bệnh về tim mạch, trầm cảm, béo phì, thậm chí có người còn nghĩ đến cái chết vì không tìm ra lối thoát. Do vậy ngoài nỗ lực của chính bản thân người bệnh, sự giúp đõ của gia đình và bạn bè để giải quyết các vấn đề có thể liên quan tới mất ngủ, cần có sự tư vấn hoặc dùng các biện pháp can thiệp điều trị của bác sĩ để giúp cải thiện giấc ngủ.

4.2. Về các triệu chứng lâm sàng liên quan giấc ngủ. Thời gian vào giấc ngủ, chất lượng giấc ngủ (tỷ lệ \% số giờ ngủ/số giờ nằm trển giường), tần suất rối loạn ngủ (số lần thức giấc sớm/tuân) là những chỉ tiêu thường được sử dụng để đánh giá tình trạng giấc ngủ[1], [3], [6]. Kết quả nghiên cứu cho thấy hầu hết các đối tượng tham gia nghiên cứu đều khó khăn khi vào giấc ngủ, $98,3 \%$ phải sau ít nhất 30 phút mới vào được giấc ngủ; $100 \%$ tự đánh giá chất lượng giấc ngủ của bản thân ở mức trung bình và kém, $68,3 \%$ có số lần thức giấc sớm trên 3 lần/tuần. Những nhân tố này ảnh hưởng rất lớn tới giấc ngủ của người bệnh, thời lượng giấc ngủ trung bình trong đêm chỉ đạt 4,02 $\pm 0,53$ giờ. Kết quả này tương tự nhận định của nhiêu tác giả về biểu hiện mất ngủ: Nguyễn Văn Tâm (2019) nghiên cứu trên 110 BN mất ngủ không thực tổn nhận thấy $62,73 \%$ BN thức giấc sớm trền 3 lần/tuần, tỷ lệ hiệu quả giấc ngủ dưới $65 \%$ chiếm tới $84,54 \%$, thời lượng giấc ngủ trung bình trong đêm $3,46 \pm 0,95$ giờ[3].

Thang điểm (PSQI) điểm là một trong những tiêu chí khách quan để đánh giá chất lượng giấc ngủ và mức độ mất ngủ thông qua hệ số tính điểm với 7 chỉ tiêu được lượng hóa. Thời lượng giấc ngủ càng gần với con số theo sinh lý giấc ngủ bình thường sẽ giúp cơ thể được nghỉ ngơi, các cơ quan được giải phóng khỏi mệt mỏi sau môtt ngày hoat động liên tục để tái tạo sức lao động cho một ngày mới, tạo cho con người sự khoẻ khoắn và sảng khoái sau mỗi đêm thức dậy. Điểm đánh giá chất lượng giấc ngủ PSQI trung bình trong nghiên cứu của chúng tôi là 14,09 \pm 2,22 . Kết quả này cho thấy chất lượng giấc ngủ của các đối tượng tham gia nghiên cứu là không tốt, đây có thể được xem như là một trong những nguyên nhân gây nên rối loạn tâm tính, sai sót trong lao động, trong các hoạt động tại gia đình và xã hội. Điều này phù hợp với nhận định của nhiều tác giả, mất ngủ gây nên hậu quả nghiêm trọng trong các rối loạn chức năng ban ngày, rối loạn tâm thần, và tăng nguy cơ gây tai nạn và chấn thương do tai nạn[3], [5], [6], [7]...

Mất ngủ kéo dài, thời lượng giấc ngủ không đủ kèm thêm với tình trạng thức giấc sớm sẽ dẫn tới hàng loạt các rối loạn khác của cơ thể với các biểu hiện iâm sàng thường gặp kèm theo như mệt mỏi $(100 \%)$, hoa mắt chóng mặt $(96,7 \%)$, hay quên $(76,7 \%)$, giảm tập trung chú ý $(75 \%)$, lo lắng $(70 \%)$, dễ cáu gắt $(53,3 \%)$. Đây là những triệu chứng lâm sàng thứ phát xuất hiện sau khi mất ngủ, do cơ thể không được nghỉ ngơi, năng lượng bị tiêu phí, không có đủ thời gian cho sự hồi phục năng lượng sau một ngày làm việc. Khi chất lượng giấc ngủ được cải thiện thì các triệu chứng này sẽ giảm và hểt. Khi đánh giá những biểu hiên lâm sàng kèm theo, nhiêu tác giả cũng có chung nhận định[3], [6]. 


\section{KẾT LUẬN}

- Tất cả các bệnh nhân mất ngủ không thực tổn thể tâm tỳ hư đều đánh giá chất lượng giấc ngưở mức trung bình và kém với điểm PSQI trung bình 14,09 $\pm 2,22$ (điểm). Thời lượng giấc ngủ trung bình trong đêm 4,02 $\pm 0,53$ (giờ).

- Có mối liên quan giữa tình trạng mất ngủ không thực tổn với tuổi, nghề nghiệp, tình trạng hôn nhân và tiền sử sang chấn tâm lý.

\section{TÀI LIÊU THAM KHẢO}

1. Bộ môn Tâm thân - Trường Đại học Y Hà Nôi (2006). Rối loạn giấc ngủ không thực tổn. Giáo trình Tâm thần học dành cho bác sĩ đa khoa, NXB Y học, Hà Nội, 62-68.

2. Bộ môn $Y$ học cổ truyên - Hoc viện quân $Y$ (2008). Thất miên. Bệnh học nội khoa y học cổ

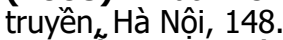

3. Nguyến Văn Tâm (2019). Nghiên cứu độc tính,tác dụng an thân trên thực nghiệm và điều trị mất ngủ không thực tổn trên lâm sàng của cao lỏng Dưỡng tâm an thần, Luận án tiến sĩ y học, Học viên Y Dược học cổ truyền Việt Nam.

4. Bố Y tế (2016). Quyết định số 3465/QĐ-BYT ngày $8 / 7 / 2016$ về viẹc ban hành bộ mã danh mục dùng chung trong khám bệnh, chữa bệnh và thanh toán bảo hiếm y tế. Phu lục: Danh muc bệnh theo ICD-10.

5. Wilson S, Nutt D (2008). Insomnia: guide to diagnosis and choice of treatment. Prescriber, 19 (8), 14-24.

6. Nguyê̂n Ngọc Đăng (2020). Đánh giá tác dụng điêu trị mất ngủ không thực tổn của viên nén İch khí an thần - HVY trên lâm sàng, Luận văn Thạc sĩ Y học, Hoc viên $Y$ Dược học cổ truyền Việt Nam.

7. Zhang M, Xu G, Luo C (2016). Qigong Yi Jinjing Promotes. Pulmonary Function, Physical Activity, Quality of Life and Emotion Regulation SelfEfficacy in Patients with Chronic Obstructive Pulmonary Disease: A Pilot Study. J Altern Complement Med, 22 (10), 12-14.

\section{MỐI TƯƠNG QUAN GIỮA ĐĂC ĐIỂM KHÁNG THUỐC LÂM SÀNG, CÂN LÂM SÀNG CỦA BỆNH NHÂN LAO PHỔI TÁI PHÁT SAU 2 THÁNG ĐIỀU TRI}

\section{TÓM TẮT}

Mục tiêu: Nghiên cứu mối tương quan giữa đăc điểm k̉ kháng thuốc với lâm sàng, cận lâm sàng của bệnh nhân lao phổi tái phát. Đối tượng và phương pháp: Nghiên cứu tiến cứu, mô tả cắt ngang, theo dõ̃i dọc trên 56 bệnh nhân lao phổi tái phát được đăng ký điều trị nội, ngoại trú tại Bệnh viện Phạm Ngọc Thạch, thành phố Hồ Chí Minh, trong thời gian 02 tháng. Kết quả: Các triệu chứng sốt, ho, khó thở gặp nhiêuu ở bệnh nhân đớn kháng. $X$ quang: Tổn thương mức độ hẹp BN lao phổi đa kháng cao hơn nhóm đớn kháng( $50 \%$ so với $25 \%$ ). Mức độ vửa và mức độ rộng chỉ gặp ở nhóm đơn kháng (kháng INH), khổng gặp ở nhóm đa kháng. Hang lao gặp $100 \%$ ở bệnh nhân đa kháng, đơn kháng gặp 25\%. Mức độ AF́B đờm liên quan tới đặc điểm kháng thuốc: Nhóm BN AFB (1+) có 7 BN nhóm kháng INH và $3 B N$ nhóm kháng RMP + INH. BN AFB $(2+)$ gặp nhóm kháng INH là $3 B N$ và nhóm kháng RMP + INH là 1 BN. BNAFB $(3+)$, gặp 2 BN ở nhóm kháng INH, và 1 BN ở nhóm kháng RMP + $\mathrm{INH}$. Nhóm BN kháng INH và kháng RMP + INH không có sự khác biệt về mối liên quan giữa các mức độ AFB (+). Kết luận: Lao phổi kháng thuốc có nhiều điểm khác biệt về lẩm sàng và cận lâm sàng so với lao phổi mới. Việc đánh giá mối tương quang giữa LS, CLS với đặc tính kháng thuốc của lao phổi có nhiêuu ý nghĩa

*Đại học Y khoa Phạm Ngọc Thạch

Chịu trách nhiệm chính: Đặng Vĩnh Hiệp

Email: hiepdv@pnt.edu.vn

Ngày nhận bài: 4/11/2020

Ngày phản biện khoa học: 20/12/2020

Ngày duyệt bài: 19/1/2021

\section{Đặng Vĩnh Hiệp*}

cho việc điều trị và dự phòng lao.

Từ khóa: Lao phổi kháng thuốc, lao đa kháng, lao đơn kháng, lao tái phát.

\section{SUMMARY}

\section{CORRELATION BETWEEN CLINICAL} PARACLINICAL WITH RESISTANT CHARACTERISTIC IN RECURRENT TB PATIENTS

Purpose: Research on the correlation between clinical, para - clinical with resistant characteristic in recurrent TB patients. Objective and method: $A$ prospective, cross-sectional study of 56 recurrent tuberculosis patients were diagnostic and treatment at Pham Ngoc Thach Hospital, Ho Chi Minh City in 2 months. Analysis of algorithm data base on statistical software and give results to research objectives. Results: Fever, cough and breathing difficulties symptoms were common in single drug- resistant TB patient. Chest $X$ ray findings:Mild level lesion in multi - resistant TB(approximate $50 \%$ ) was more commonly than single - resistant TB (approximate 25\%). Moderate and severe lesion were only in the single resistant TB. TB cavity was in all multi - resistant TB patient and about $25 \%$ in single - resistant TB patient. The correlation between positive AFP sputum smears results and resistant characteristic: Pulmonary TB patients with AFB smear-positive $(1+)$ include 7 patients with INH resistance and 3 patients with RMP + INH resistance. Pulmonary TB patients with AFB smear-positive $(2+)$ include 3 patients with INH resistance and 1 patient with RMP + INH resistance. Pulmonary TB patients with AFB smear-positive (3+) include 2 patients with INH resistance and 1 patient with RMP + INH resistance. Pulmonary 